\title{
POSIBILIDADES Y LIMITACIONES DEL USO DE LA PRENSA COMO FUENTE PARA LA RECONSTRUCCIÓN DE LA HISTORIA POLÍTICA EN EL NORDESTE ARGENTINO: ALGUNAS NOTAS SOBRE CORRIENTES Y CHACO (PRIMERA MITAD DEL SIGLO XX)
}

\author{
Possibilities and Limitations of the use of the Press as a source for the \\ reconstruction of political history in Northeast Argentine: some notes on \\ Corrientes and Chaco (First half of the XX Century)
}

\author{
María del Mar Solís Carnicer* \\ https://orcid.org/0000-0002-5065-3611 \\ Mayra Maggio** \\ https://orcid.org/0000-0002-0305-3701
}

\begin{abstract}
Resumen
En este trabajo nos proponemos reflexionar sobre los usos, posibilidades y limitaciones de la prensa como fuente para la reconstrucción de la historia de los partidos políticos en el nordeste de Argentina, especialmente en dos jurisdicciones Corrientes y Chaco en la primera mitad del siglo XX. Estos espacios comparten una cercanía geográfica pero cada uno de ellos tienen características particulares, desde los modos y tiempos de sus dinámicas políticas y sociales hasta la inserción en el esquema económico nacional.

Desde un abordaje comparativo, si bien será una primera aproximación, pretendemos reflexionar sobre los usos de la prensa como fuente para las investigaciones de la historia política regional, considerando que ésta constituye, en gran parte, uno de los principales materiales disponibles para el historiador.
\end{abstract}

$<$ Prensa $><$ Historia política $><$ Corrientes $><$ Chaco $>$

\begin{abstract}
In this work we reflect on uses, possibilities and limitations of the press as a source to reconstruct the history of political parties in the northeast of Argentina, especially in two jurisdictions: Corrientes and Chaco in the first half of the 20th century. These spaces share a geographical proximity but each of them have particular characteristics, from the modes and times of their political and social dynamics to their insertion in the national economic scheme. From a comparative first approach, we analyze the uses of the press as a source of research of the regional political history, wichi is, to a large extent, one of the main materials available to the historian.

$<$ Press $><$ Political history $><$ Corrientes $><$ Chaco $>$

Recibido: 01/11/2018// Aceptado: 05/12/2018

* Dra. en Historia. Investigadora Independiente del CONICET. IIGHI-UNNE-CONICET. Profesora titular de la Facultad de Humanidades de la UNNE.marimarsolis@yahoo.com.ar

** Especialista en Historia Regional. Lic. en Historia por la Universidad Nacional del Nordeste. Becaria Doctoral del CONICET, IIGHI-UNNE-CONICET. mayitamaggio@hotmail.com
\end{abstract}


Solís Carnicer y Maggio. Posibilidades y limitaciones del uso de la prensa como fuente para la reconstrucción de la...

\section{Introducción ${ }^{1}$}

Es cada vez más frecuente que los historiadores recurran a la prensa escrita como fuente para sus investigaciones, especialmente para el caso de las historias regionales o locales donde muchas veces no se cuenta con otro tipo de documentación. La prensa escrita se define como "un documento cultural y pertenece al amplio tipo de fuentes en los que es posible separar un soporte de un contenido y que transmiten un mensaje más o menos formalizado" (Aróstegui, 2001: 383). En la prensa, el historiador encuentra datos y noticias de todo tipo de acontecimientos, el periodista que es testigo de la realidad día a día la transmite en un medio de apariencia efímera, pero de valor testimonial decisivo para los investigadores que luego han de re-construir la historia.

En estas notas nos proponemos reflexionar sobre los usos, posibilidades y limitaciones de la prensa como fuente para la reconstrucción de la historia política en el nordeste de Argentina, especialmente en dos espacios próximos, pero bien diferenciados: Corrientes y Chaco en la primera mitad del siglo XX. Ambos comparten una cercanía geográfica pero cada uno de ellos tiene características particulares, desde los modos y tiempos de sus dinámicas políticas y sociales hasta la inserción en el esquema económico nacional. Corrientes, cuya capital fue fundada en 1588, constituyó una de las primeras catorce provincias argentinas y participó de la conformación del Estado Nacional, mientras que Chaco fue organizado en el marco de los "Territorios Nacionales", que eran distritos dependientes de las autoridades nacionales, que funcionarán como entidades provisorias a partir de 1884 y que recién alcanzarán el rango de provincias en 1951. Por lo tanto, desde este abordaje comparativo -si bien será planteada como una primera aproximación- pretendemos reflexionar sobre los usos de la prensa como fuente para las investigaciones de la historia política regional, considerando que ésta constituye, en gran parte, uno de los principales materiales disponibles para el historiador.

\section{I- La prensa escrita como objeto y como fuente: algunas consideraciones}

La prensa -por el tipo de información que ofrece- es una de las fuentes más utilizadas para el estudio de las historias políticas provinciales o locales (Macor, 2014). Sin embargo, ésta no es su única utilidad, los medios escritos pueden ser también un interesante objeto de investigación en sí mismos. Por otra parte, en la prensa auto concebida como de "combate" los rectores de la publicación pueden identificarse con mayor claridad, por lo que su análisis se inclina naturalmente hacia el tema de su impacto político.

Una de las tantas formas de estudiar las relaciones entre prensa y política es la que pone el acento en la interpretación de los medios de comunicación entrelazados en redes

\footnotetext{
Una versión preliminar de este trabajo fue presentada en la mesa "Problemas de la historia política en los espacios provinciales y regionales: del reformismo a las transiciones democráticas (1880-1983) en el marco del XXXVIII Encuentro de Geohistoria Regional, coordinado por Natacha Bacolla (UNLCONICET/UNR), Yolanda Urquiza (UNaM) y María del Mar Solís Carnicer (IIGHI-CONICET/UNNE). Agradecemos especialmente los comentarios de las coordinadoras y del público presente. Los errores son de nuestra exclusiva responsabilidad.
} 
de relaciones institucionales (Da Orden y Melón Pirro, 2007). En esta línea se inscriben aquellos estudios que indagan a los medios en su función de órgano difusor de partidos o líderes políticos. En este caso el foco está puesto en la capacidad que tienen los medios para funcionar como "tribunas" ante la complejización del espacio público (Duncan, 2007 y Sidicaro, 2009). Desde esta posición, la relación prensa-política se teje en la necesidad de amplificar la voz de un partido ante la sociedad civil. A su vez, la modernización de los medios de comunicación y su creciente autonomía pone, desde esta perspectiva, a la prensa como un actor político más, capaz de influir en el juego de lo político. En este tipo de abordaje el análisis también se centra en las características político-ideológicas de sus propietarios (Zimmermann, 1996 y Saìtta, 1998). En este sentido, Mirta Kircher afirma: "La prensa en tanto vidriera política se convierte en un lugar inestimable para pensar la política y la sociedad, pero también permite visualizar la peculiaridad del objeto, inscripto permanentemente en un campo de relaciones que involucra poderes, actores, fuerzas políticas y en la producción y puesta en circulación de temas y argumentos destinados a intervenir en el debate político y cultural" (Kircher, 2005).

El reconocido historiador francés Fernand Braudel señalaba lo "encantador" que resultaba el trabajo con la prensa, pues ella permitía "pasar revista a un caleidoscopio de variadas situaciones y personajes" (Braudel, 2002). Desde la perspectiva del trabajo del historiador, la prensa es siempre una referencia parcial y fragmentaria de la realidad, su posibilidad de convertirse en fuente dependerá no solo de la cantidad de respuestas que ésta brinde a las preguntas que el investigador le formule sino también de la disponibilidad de los recursos metodológicos para la crítica de la fuente y de técnicas de recolección de análisis e interpretación de los datos que obtenga (Kircher, 2005). Al trabajar con la prensa como fuente histórica, el investigador debe tener presente que se trata de una representación de la realidad hecha por sus redactores quienes la ofrecen a los lectores, los que a su vez la integran a sus propias representaciones e imaginarios. Es decir, se produce un juego dialéctico, que el historiador busca reconstruir o entender.

Como con cualquier otro tipo de fuente, el trabajo con la prensa requiere que el investigador tenga conciencia de la incidencia de su propia subjetividad en la interpretación de los hechos, puesto que también dialoga con las representaciones que subsisten en los textos. Es importante tener en cuenta que el uso de la prensa como fuente debe hacerse con un análisis crítico riguroso puesto que por sus especiales características requiere ser confrontada y decodificada, a fin de lograr los grados de certeza, verosimilitud y credibilidad que requiere la investigación histórica. Otro elemento a tener en cuenta es la calidad de la información que la prensa brinda, ésta debe ser confrontada y criticada puesto que pueden ofrecernos informaciones falsas o incompletas, o directamente omitirlas. El periódico debe comprenderse en su contexto, teniendo en cuenta los intereses que representó, los valores que canalizó, su rol dentro del sistema informativo y su articulación con otros medios y como representante de ciertos grupos o sectores sociales. Es fundamental la contextualización, puesto que ésta permitirá comprender más cabalmente la información que brinda (Morán y Aguirre, 2008). 
Solís Carnicer y Maggio. Posibilidades y limitaciones del uso de la prensa como fuente para la reconstrucción de la...

Según Paula Alonso, a fines del siglo XIX, los periódicos lograron "republicanizar la política" y convertirla en una cosa pública, expandiéndola más allá de las pequeñas reuniones de círculo en los cafés, clubes o comités, pues en estas publicaciones se hacía el seguimiento cotidiano de los principales eventos, se difundían noticias de cismas partidarios y de reuniones políticas, y se revelaban los celos, rivalidades, alianzas y traiciones. Por otra parte, al mismo tiempo que hacían de la política una cosa pública, integraban al público a la política. Esta circunstancia obligó a los diferentes actores políticos a formular sus discursos cuidadosamente y elaborar un lenguaje principista y altruista en la defensa de sus políticas. Al mismo tiempo, el estilo batallador, agudo e irónico empleado en las columnas de la prensa hacía difícil la retractación, encasillando tanto al gobierno como a la oposición en posturas muy rígidas, que dificultaban el cambio de discurso y provocaba situaciones embarazosas cuando alguna cuestión particular así lo requería (Alonso, 1997).

Esas características de la prensa política Argentina de fines del siglo XIX, podrían extenderse a la prensa regional de las primeras décadas del siglo XX (de acuerdo con el creciente número de trabajos que se están dedicando al estudio de la prensa política en este siglo $)^{2}$. A través de sus páginas, no sólo pueden seguirse los acontecimientos políticos del período, sino que a través de sus editoriales se pueden establecer las representaciones que cada sector construyó sobre sí mismo y sobre sus adversarios.

\section{II- El desarrollo de la prensa escrita en Corrientes y Chaco hasta 1950: itinerarios y protagonistas}

En el desarrollo de la prensa escrita, tuvieron impacto las características políticas y sociales claramente diferenciadas de estos espacios ${ }^{3}$. Para el caso correntino, la prensa

2 Sin pretender ser exhaustivos, pueden mencionarse los trabajos de Sidicaro, 1993; Tato, 2004; Pasquali, 2001; Ulanovsky, 1997; Prislei, 2001y Alonso, 2004.

${ }^{3}$ En el caso de Corrientes fue una de las primeras catorce provincias argentinas, sin embargo, no pudo incluirse satisfactoriamente en el proceso de transformación económica que se produjo en el país a fines del siglo XIX bajo el modelo agroexportador, quedando relegada a un lugar marginal tanto desde el punto de vista económico como político. Su rica y peculiar historia política estuvo marcada por el predominio de los partidos políticos provinciales de corte conservador (Autonomista y Liberal) quienes gobernarán la provincia desde fines del siglo XIX hasta mediados del siglo XX. A partir de 1909 se incorpora a la competencia política el partido radical como un partido organizado que, a pesar del gran apoyo popular que tuvo, no consiguió acceder al poder político de la provincia hasta 1946, año en que Juan Domingo Perón accede al gobierno de la república, siendo Corrientes la única en la que triunfó el radicalismo. El peronismo recién llegará al poder provincial luego de una intervención federal en septiembre de 1947, permaneciendo en el gobierno hasta el golpe de 1955 (Solís Carnicer, 2006).

Por su parte, el Chaco fue uno de los últimos espacios que se incorporó bajo el control del Estado nacional a fines del siglo XIX. La ley $\mathrm{N}^{\circ} 1532$ de 1884 organizó estas dependencias bajo la denominación de "Territorios Nacionales" que carecían de autonomía política y presupuestaria y cuyo gobernador era designado por el PEN con acuerdo del Senado, función en la que duraba tres años con posibilidad de continuar por un nuevo período. Si bien su existencia fue considerada una cuestión transitoria y temporal, esta situación jurídica se prolongó hasta mediados del siglo XX en que fueron adquiriendo progresivamente el estatus de provincias. El único ámbito donde sus pobladores participaban en elecciones eran las localidades de más 1000 habitantes donde se elegía un concejo municipal de 5 miembros que se renovaba cada dos años (Leoni, 2001). A fines de la década de 1940 el territorio contaba con 10 municipios electivos: Resistencia, 
fue siempre un actor clave no solo por la minuciosa reconstrucción que allí se hacía de cada uno de los partidos y procesos políticos sino también por la interpretación que ofrecían. Asimismo, cada partido político o facción se preocupaba permanentemente por tener una publicación periódica que lo representara y oficiara de vocero, observándose una estrecha y al mismo tiempo compleja relación entre la prensa y la política. Si bien resulta difícil definir el público al cual esta prensa estaba dirigida, es posible suponer que se trataba de un sector minoritario de la población, fundamentalmente militante o adherente a los diferentes partidos a los cuales los periódicos decían representar ${ }^{4}$.

Desde fines del siglo XIX a mediados del siglo XX, Corrientes experimentó un gradual incremento de su población, aunque disminuyendo paulatinamente su ritmo. Una de las principales causas que explica esta cuestión es el fenómeno de la emigración ${ }^{5}$. El hecho de que Corrientes fuera excluida de la zona de desarrollo vinculada al mercado externo, tuvo repercusiones en el aporte inmigratorio que recibió, pues no logró constituirse en una región atractiva para el inmigrante europeo. La mayoría de la población de la provincia se ubicaba en la zona occidental, siendo la Capital -la ciudad- que concentraba la densidad más importante ${ }^{6}$. Sin embargo, la mayor parte de los correntinos vivía en zonas rurales (70,2\% en $1895,62,8 \%$ en 1914 y $65,75 \%$ en 1947). Otra cuestión a tener en cuenta es la cantidad de población analfabeta, si bien el porcentaje era muy elevando, el mismo evidenció un significativo descenso durante estos años ${ }^{7}$. Estos números son importantes pues nos dan una idea de lo limitado del círculo de lectores que estas publicaciones podían tener.

Presidencia Roque Sáenz Peña, El Zapallar, Quitilipi, Villa Ángela, Charata, Presidencia de la Plaza, Machagai, General Pinedo y Puerto Bermejo. En el caso del Chaco, recién alcanzará el rango de provincia en 1951, a fines de la primera presidencia de Juan Domingo Perón. En cuanto a la participación política, la disputa por los cargos estuvo dada por los partidos tradicionales de alcance nacional que se organizaron en el territorio como la Unión Cívica Radical y el Partido Socialista, y diversas expresiones locales como la Unión Popular, Defensa Vecinal, Unión Vecinal o bien facciones ocasionales de los partidos mayoritarios. En la década de 1930 y principios de 1940 tuvieron presencia tanto extracciones conservadoras como la Concordancia del Chaco y el Partido Demócrata Progresista, como del Partido Comunista, pero con un grado de influencia más bien reducida en el electorado. La disputa en las elecciones de la capital y de la segunda ciudad del territorio- Resistencia y Sáenz Peña- se dio principalmente entre el radicalismo y el socialismo, que reunían el mayor caudal de votos (Maeder, 1997 y Leoni, 2002).

${ }^{4}$ La Capital era la ciudad que contaba con más publicaciones, pero también existían periódicos en diferentes localidades del interior de la provincia. El universo era bastante diverso, pero en general, la mayoría respondía a las características de la prensa política. En nuestro caso hemos trabajado únicamente con los ejemplares que se encuentran en el Archivo General de la provincia de Corrientes, aunque sabemos de la existencia de otros.

5 La provincia pasó de 239.618 habitantes en 1895 a 525.463 en 1947. Segundo Censo Nacional. Tomo II. Población, Buenos Aires, Taller Tipográfico de la Penitenciaría, 1898, Tercer Censo Nacional (1914) Tomos II y IV. Población. Buenos Aires, Talleres Gráficos de L. J. Rosso y Cía, 1916, IV Censo General de la Nación. Tomo I, Censo de Población. Buenos Aires, Dirección Nacional de Servicio Estadístico, 1947. P. Benjamín Serrano. Guía General de la Provincia de Corrientes 1910. Corrientes, Talleres de Teodoro Heinecke, 1910 y José Francisco de Bosini. Guía General de la Provincia de Corrientes Años 1934- 1935, Corrientes, Imprenta del Estado, 1935.

6 En 1895 concentraba el $30 \%$ del total de la población provincial, pero paulatinamente va disminuyendo en importancia ( $26 \%$ en 1914 y 10,76\% en 1947).

7 Del total de la población correntina mayor de 6 años en 1895 el 74,6\% eran analfabetos; en 1914 del total 
Solís Carnicer y Maggio. Posibilidades y limitaciones del uso de la prensa como fuente para la reconstrucción de la...

Los periódicos fueron un elemento fundamental de la política partidaria de Corrientes puesto que se constituyeron en uno de los principales factores que mantuvo activa su vida política. Hasta la llegada del peronismo en el que se plantearon ciertas restricciones, la libertad de prensa estuvo garantizada, lo que permitió la publicación de un importante número de periódicos y revistas. Entre estas publicaciones, la prensa política cumplió un rol fundamental, que consistió en forjar la imagen pública del partido o facción política a la que representaba, al mismo tiempo que se convirtió en un foro de reunión para los miembros del grupo. A través de sus páginas, no solo pueden seguirse los acontecimientos políticos del período, sino que a través de sus editoriales se pueden establecer las representaciones que cada sector construyó sobre sí mismo y sobre sus adversarios.

Cada partido, incluso las facciones, contaba con su órgano oficial, y era una preocupación constante en las convenciones partidarias el tema, pues estas publicaciones, eran costeadas en gran parte, por los afiliados. Tenían un carácter netamente faccioso y las noticias que publicaban eran casi exclusivamente de política partidaria (la conformación de comités, la organización de reuniones, la elección de autoridades y candidatos, etc.), siempre con una nota editorial que reflejaba el pensamiento del partido frente a diferentes temas de la actualidad política. Podemos afirmar que la prensa política constituyó un actor político más dentro del sistema (Borrat, 1989).

Muchos de estos periódicos forman parte de la rica hemeroteca del Archivo General de la Provincia de Corrientes que cuenta con un índice general en el que consta el nombre del periódico, su lugar de edición y los ejemplares existentes en el repositorio, ordenados por fechas. La mayoría de estos diarios están archivados en cajas, los menos (especialmente los más antiguos) se encuentran encuadernados. Muchos de ellos se encuentran en mal estado de conservación, lo que hace imposible su consulta. En los últimos tiempos se ha iniciado un proceso de digitalización de los mismos que al tiempo que colabora en su preservación como fuente facilita el acceso a los mismos a los investigadores interesados en su consulta ${ }^{8}$.

Como ya señalamos, la provincia de Corrientes se caracterizó por contar con un nutrido grupo de publicaciones periodísticas, muchas de ellas facciosas desde fines del siglo XIX ${ }^{9}$. Sin pretensiones de exhaustividad podemos mencionar algunos de los

de la población correntina mayor de 7 años, 55,5\% eran analfabetos y en 1947 el 31, 11\% de la población mayor de 14 años era analfabeta.

8 Como parte de un proyecto del NECEPS se encuentra en preparación un repositorio digital de periódicos de la región construido a partir del importante trabajo de digitalización que diferentes investigadores han realizado en el marco de diferentes proyectos de investigación, en especial el PI "Tensiones, rupturas y continuidades. La relación entre prensa y política en la provincia de Corrientes (1880-1990)" dirigido por María del Mar Solís Carnicer y desarrollado entre los años 2013 y 2016.

9 La historia de la prensa en la provincia de Corrientes es aún una tarea por realizar. Aunque contamos con algunos antecedentes que merecen mencionarse aquí, los estudios de Manuel Florencio Mantilla (1887) y Emilio Méndez Paz (1953). Ambos hacen una breve enumeración descriptiva de las publicaciones periódicas existentes en la provincia desde mediados del siglo XIX hasta 1900. Por otra parte, resulta de interés mencionar también aquí los aportes de Gabriel Feris (1992) y Dardo Ramírez Braschi (2004). En el primer caso, se trata de un interesante relato rico en anécdotas y desde la propia experiencia en el periodismo y la política en 
principales periódicos representativos de los diferentes sectores políticos en las primeras décadas del siglo XX. Así, entre los periódicos radicales, que se reconocieron como órganos oficiales del partido podemos mencionar a Alem, que se publicó entre 1912 y 1916, su director fue Eudoro Vargas Gómez y actuaban como secretarios Amado Sosa y Luis Zervino, todas importantes figuras del radicalismo en esos años. El Civismo que se empezó a editar en la localidad de Saladas, también en 1912, en este caso se trató de un Semanario que salía los sábados dirigido por Vicente Flores. Paladín Radical, un diario que salió entre 1918 y 1919 dirigido por Ángel Ergasto Blanco ${ }^{10}$ y Los Principios que fue representativo del radicalismo disidente y La Opinión, que se comenzó a publicar en Corrientes en el año 1909 dirigido por J. Fernández de la Fuente. En la década del '30 se sumarán a este grupo Voz Radical, dirigido por Porfirio Aquino y Nueva Época, dirigido por Francisco Rivellini que representaba los intereses del partido radical antipersonalista.

Entre los periódicos autonomistas figuró La Provincia que se proclamó órgano del partido autonomista, aunque en realidad representaba solamente al sector principista. Empezó a publicarse en 1916 y salía tres veces a la semana (martes, jueves y sábados). Sin proclamarlo abiertamente El Liberal (desde el año 1916 propiedad de Juan Ramón Vidal, principal dirigente del partido autonomista hasta su muerte en 1940), también representó a los intereses del partido autonomista. A partir de 1930 se sumó a este grupo el diario La Mañana propiedad de Elías Abad, un importante dirigente de ese partido durante las décadas de 1930 a 1958.

Algunos de los periódicos liberales fueron La Libertad (liberal mantillista que dejó de publicarse en 1910) que apareció por primera vez el 9 de julio de 1877, y se convirtió en órgano oficial del partido en agosto de 1878. Su fundador fue Manuel Florencio Mantilla que lo dirigió en sus tres primeras épocas. En la cuarta el director fue Vicente F. Esquivel. En 1898, asumió ese lugar Manuel Pedevilla, en 1903 Ramón Díaz de Vivar y en 1908 Luis R. Monje. Participaron como redactores Angel Esquer, Pedro R. Fernández, Emilio Díaz, Miguel G. Morel y Eudoro Díaz de Vivar. En 1910 se volvió el órgano Oficial del sector denominado Unión Cívica y desde sus páginas hicieron propaganda en contra del partido autonomista y luego también del martinismo (Méndez Paz, 1953). La Constitución (representante del partido Demócrata y luego de la Concentración Cívica) se publicó sólo entre 1916 y 1920, El Orden, en una segunda época, hacia 1921, también fue su órgano oficial, La Unión, semanario que se empezó a publicar en Goya en 1907, que sostenía los principios del partido liberal martinista y El Liberal (antes de 1916 también representaba a este partido).

Entre todos los periódicos liberales se destaca en este período El Día (que empezó a publicarse en 1921), como "Órgano independiente, noticioso y de intereses generales"

Corrientes y en el segundo, un profundo estudio sobre la prensa política de Corrientes durante el período de la guerra de la Triple Alianza, analizando el abordaje que los periódicos locales hicieron de dicho conflicto. Por otro lado, debemos mencionar el artículo de Solís Carnicer, Chao y Ayala, 2013 y los trabajos que está realizando Andrea de los Reyes sobre la prensa correntina durante el peronismo.

${ }^{10}$ Empezó a publicarse en 1918, bajo la dirección de Ángel Ergasto Blanco y en él colaboraron José R. Turnillo, Emilio R. Oliver, Francisco Benítez y otros. Véase: M. Herrera. Cit. p. 399. 
Solís Carnicer y Maggio. Posibilidades y limitaciones del uso de la prensa como fuente para la reconstrucción de la...

aunque reflejaba en sus inicios ciertas simpatías con la Asociación Comercial de Corrientes (un organismo gremial que participaba en las elecciones municipales). Pronto empezará a representar abiertamente el pensamiento del partido liberal, especialmente del sector rupturista desde 1927. A pesar de su contenido político abiertamente faccioso, este diario, de ocho páginas, incluyó otras secciones, y numerosas noticias telegráficas nacionales e internacionales. Posteriormente se sumará a la prensa liberal El Noticioso que se publicó hasta 1948.

Durante la corta actuación del partido Republicano en 1909, éste también tuvo su órgano de difusión, el periódico El Orden, dirigido por Andrés Demarchi, un ciudadano brasileño que, a su vez, era jefe de ese partido ${ }^{11}$. El periódico pasó luego a representar al martinismo, lo que motivó la renuncia de sus dos principales redactores: Francisco Benítez y Martín Abelenda ${ }^{12}$.

En estos años también se publicó un periódico católico denominado Corrientes (que salió entre 1911 y 1917). Éste último, también discutió temas políticos y fue acérrimo opositor tanto del gobierno de Vidal (1909- 1913) como del de Mariano Loza (1913- 1916). Finalmente, el obispo Niella determinó que dejara de publicarse ante la extrema politización que adquirió el periódico en 1917. Hubo, además, algunos periódicos con una línea editorial más independiente como Tribuna Popular, que se empezó a editar en Corrientes en 1921, aunque en él se advierten simpatías hacia el sector radical.

La mayoría de estas publicaciones tuvo escasa continuidad, una tirada pequeña y un número de páginas que generalmente no superaba las cuatro (las únicas excepciones fueron El Liberal en una segunda etapa, El Día y Tribuna Popular). En la primera o segunda página se volcaba el núcleo de la información del diario, allí aparecían las noticias partidarias (reuniones, comités, candidatos) y la nota editorial, generalmente anónima, que registraba la opinión del diario sobre diferentes temas de la actualidad política local y en menor medida nacional. En las demás, se incluían avisos clasificados e informaciones telegráficas y en algunos casos alguna sección social o deportiva. También era muy común reproducir notas periodísticas publicadas en periódicos de Buenos Aires que representaran al mismo sector político del diario local. Solo algunos de ellos se publicaron diariamente (Alem, El Liberal, El Día, El Orden, La Opinión, Tribuna Popular y Paladín Radical), los demás salían una o dos veces por semana.

Para mediados de la década de 1940, momento en que surge el peronismo se publicaban en la ciudad de Corrientes un nutrido número de periódicos y revistas que representaban a los diferentes sectores políticos ${ }^{13}$. Más allá de que para la misma época algunos diarios ya publicaban ediciones a color, en Corrientes todos los periódicos se editaban en blanco y negro. Posteriormente, se sumaron nuevos medios que se identificaron

\footnotetext{
${ }^{11}$ La Libertad, Corrientes, 9 de febrero de 1909. p. 2.

${ }^{12}$ La Libertad. Corrientes, 17 de marzo de 1909. p. 2.

${ }^{13}$ El 28 de mayo de 1945 se organizó el Círculo de Periodistas de Corrientes que integraron representantes de cada uno de estos medios, así como también corresponsales de United Press, Crítica, La capital (Rosario), El Litoral (Santa Fe) y El cronista Comercial. DF, 29/5/1945.
} 
con el peronismo y representaban a diferentes líneas internas del partido como El Diario del Foro (representaba a la línea de Filomeno Velazco) y Sapucay (representaba a la línea de Daniel Mendiondo). De a poco, a lo largo de esa década, algunos de los antiguos periódicos opositores desaparecieron o cambiaron su línea editorial. Hacia 1955 sólo se publicaban en la ciudad dos periódicos oficialistas (El Liberal y La Calle) y un diario opositor (La Mañana). El Diario del Foro dejó de ser un diario judicial en 1947 para pasar a convertirse en el periódico vocero del gobernador Juan Filomeno Velazco y dejará de publicarse al terminarse su mandato. Lo reemplazó como diario oficial La Calle que pasará a representar al sector del peronismo que accedió al gobierno provincial con Benito Castillo. El Liberal, por su parte, hacia 1952 se volvió difusor de las ideas del peronismo aunque no representaba la voz oficial del gobernador. Quedó bajo la dirección del empresario de medios Enrique Jasid (quien ya había dirigido El Diario del Foro) que alquiló el diario a la sucesión de Juan Ramón Vidal.

Esta apretada descripción pone de manifiesto algunos de los rasgos de la prensa correntina de la primera mitad del siglo XX. Más allá de algunos casos excepcionales, la mayor parte de estas publicaciones respondían a las características de la prensa facciosa propia del siglo XIX. Se trataba fundamentalmente de prensa partidaria que estaba destinada principalmente a los propios militantes o adherentes del partido o agrupación a la que representaba. Como vimos, la heterogeneidad característica de esta prensa se vio profundamente afectada durante el peronismo aunque los rasgos fundamentales de estas publicaciones no sufrieron modificaciones internas importantes.

Para el caso chaqueño debemos tener en cuenta que en tanto Territorio Nacional los derechos políticos se sus habitantes se hallaban restringidos y las elecciones se celebraban solo en el ámbito municipal. Por las características de la ocupación y poblamiento, la sociedad chaqueña adquirió un carácter heterogéneo, desigualmente distribuida, en constante expansión y movilización hacia las fuentes de trabajo, lo que tornaba ineficaces las medidas de control tomadas por el gobierno territorial ${ }^{14}$. Pese a la imposibilidad de elegir a sus autoridades el periodismo chaqueño tempranamente se ocupó de reclamar para sí el derecho a representar a la opinión pública alcanzando una gravitación indiscutible como vocera de los intereses y aspiraciones de los habitantes del Chaco (Leoni, 2008a). La labor periodística fue inicialmente desarrollada por inmigrantes extranjeros (españoles e italianos), luego se incorporaron chaqueños y correntinos. La instalación de la imprenta de Juan Moro en Resistencia a partir de 1901 fue decisiva para la proliferación de diversos periódicos, revistas y folletos con gran calidad, ya que contaba con el mejor equipamiento de su época. Los principales

\footnotetext{
${ }^{14}$ Después de la creación de la colonia Resistencia en 1878 en el territorio se radicaron inmigrantes europeosprincipalmente italianos y españoles- sumándose a los migrantes provenientes de provincias y países vecinos, principalmente correntinos, santiagueños y paraguayos. Con ellos y la población autóctona, tras ser sometida, se constituyó la mano de obra para la explotación forestal y la cosecha del algodón, actividades que integraron al Chaco al esquema agroexportador nacional. La exigua vigilancia de los procesos productivos, la falta de infraestructura básica (servicios sanitarios, educativos, policiales) para atender una gran masa de población itinerante, sumada a las duras condiciones de trabajo que imponían estas actividades económicas, derivaron en la temprana presencia de conflictividad, traducida en huelgas agrarias y movilizaciones de obreros que fueron constantes durante los gobiernos de la década de 1930 y 1940.
} 
Solís Carnicer y Maggio. Posibilidades y limitaciones del uso de la prensa como fuente para la reconstrucción de la...

referentes de la prensa chaqueña provenían de los sectores que conformaban una suerte de elite local, vinculada al comercio y con activa participación en los círculos sociales e intelectuales y la vida política municipal, que además contaban con recursos para financiar las publicaciones (Leoni, 2008b).

Desde la prensa se alentó la participación y organización de los habitantes en torno a las instituciones políticas, sociales, culturales y deportivas locales en un esfuerzo por aunar a los chaqueños tras objetivos comunes y se promovieron las incipientes expresiones artísticas y literarias. Fue constante en las páginas la defensa de los derechos de los territorianos frente al Estado nacional, que se manifestaba en momentos tales como la renovación de las autoridades territorianas o la presentación en el Congreso Nacional de proyectos que afectaban a la vida política o económica del territorio. En todas esas discusiones, la intervención política de los directores de los periódicos fue destacada.

Como expresa Sánchez de Larramendy, no ha sido posible reconstruir íntegramente los inicios de la prensa territoriana ya que no se han preservado ejemplares de la misma hasta 1915. No obstante, tenemos indicios de que desde fines de siglo XIX aparecieron los primeros periódicos locales como El Correo del Chaco (1878), La Opinión (1882), La Revista del Chaco (1891), el diario satírico El Chucho (1891), La Veleta, El Porvenir (1893) y El Avisador del Chaco (1899). Ya en los inicios del siglo XX, aparecen el periódico El Chaco (1901-1905), El Látigo, Nueva Época, El Imparcial, El Pueblo, El Industrial (1907-1908) El Obrero (1908-1909), El Progreso, La Resistencia, El Orden, Defensa Regional, El Constitucional y La Verdad y los semanarios Punto y Coma (1916), Luz del Norte (1908) (Sánchez de Larramendy, 1988). La mayoría de esas publicaciones tuvo una vigencia efímera y su periodicidad osciló constantemente a través del tiempo, por lo que pareció más una empresa personal de sus fundadores, la mayoría inmigrantes, muy difícil de sostenerse sin ellos al frente de la misma.

El único periódico de esta primera etapa del que nos han quedado registros es El Colono (1906-1922) ${ }^{15}$, dirigido por Emilio Rodríguez Román, de origen español y radicado en el Chaco desde 1889, donde desarrolló una importante labor productiva y comercial. La línea editorial del diario estaba identificada con la labor agrícola y la defensa de la propiedad de la tierra frente a la especulación y el latifundio (de allí su nombre), aunque también propiciaban un espacio de reclamo de atención a las problemáticas locales, frente al desconocimiento de las autoridades nacionales (Sánchez de Larramendy, 1988).

Los diarios de mayor tirada y que lograron continuidad fueron La Voz del Chaco (1915-1946) y El Territorio (1919-1983). En el primer caso, fue un periódico fundado y dirigido por Ángel D'Ambra ${ }^{16}$, donde participaban referentes del anarquismo

\footnotetext{
${ }^{15}$ De El Colono se conserva una colección casi completa en la Biblioteca de la Escuela N¹ "Benjamín Zorrilla" de Resistencia. En este momento no contamos con datos sobre su estado de conservación. De enero a mayo de 1916 fue director Fernando Echeverría y de mayo a septiembre de ese año Alfredo G. Cartey. El 23 marzo de 1922 asume la dirección Enrique Lynch Arribálzaga hasta junio de 1922, en que deja de aparecer (Sánchez de Larramendy, 2006).

${ }^{16}$ Ángel D’Ambra (1888-1965) Había nacido en Caltanissetta, Sicilia (Italia). Fue uno de los primeros
} 
y socialismo, aunque procuró ser una publicación independiente. El periódico estimuló la participación política de los inmigrantes y trato de presentar en sus páginas la imagen de un Chaco progresista (Leoni, 2008b). Por su parte, El Territorio surgió en 1919 por iniciativa del periodista y poeta Raúl Gabriel Gauna, primero como semanario luego como diario ${ }^{17}$. Ligado a los referentes del radicalismo yrigoyenista en el Chaco, adquirió por temporadas una impronta combativa que le valieron varias clausuras, sobre todo luego de la llegada de Ernesto Zamudio a la dirección ${ }^{18}$. El diario se presentó como defensor de los intereses chaqueños -pero por momentos también proyectando un alcance regional- tomando parte frente al gobierno nacional en favor del desarrollo de la actividad agrícola, la explotación forestal, pero también con los obreros y profesionales ${ }^{19}$. Su derrotero marca el año 1954 como un punto de inflexión, ya que por presiones del gobierno fue vendido a la Confederación General del Trabajo. Luego de la caída del gobierno peronista en 1955, El Territorio sufrió las mismas consecuencias de los diarios "oficialistas": clausura e intervención, por lo que los directores fueron nombrados por las diferentes administraciones hasta la década de 1960. El diario sobrevivió con altibajos las etapas sucesivas hasta 1989, en que cerró definitivamente. Junto con estos periódicos publicados en Resistencia, desde la década de 1920 circulaban también diarios en localidades como Villa Ángela y Quitilipi y en la de 1930, Charata, Las Breñas, El Zapallar, Presidencia de la Plaza y Machagai, siendo los más reconocidos los diarios La Verdad y La Acción de Sáenz Peña.

Debemos detenernos en la trayectoria de la revista Estampa Chaqueña (19291943) fundada y dirigida por Ildefonso Pérez ${ }^{20}$. Esta revista, editada en Resistencia, publicaba información local sobre actividades sociales, culturales, educativas deportivas y políticas, proporcionado material que ilustraba sobre aspectos sobresalientes del territorio (Leoni, 2012). Los objetivos que perseguía eran la formación de una conciencia colectiva y de una identidad chaqueña de la que debía proceder el esfuerzo de transformación política. La revista se involucró en la arena política en diferentes ocasiones, ya sea criticando la

inmigrantes llegados a Resistencia, junto a sus padres Salvador D'Ambra y Miguelina Costa. Pionero de la industria gráfica, en 1915 con otros italianos y algunos españoles, fundaron La Voz del Chaco. Dos años más tarde fue el director del mismo. En 1920, durante el gobierno de Enrique Cáceres se clausuró el periódico y D'Ambra fue detenido y encarcelado, Desde 1930 hasta 1946 se hizo cargo de la dirección del periódico su hermano Luis. Se distinguió también como gran colaborador en distintas instituciones. Falleció en Resistencia. (Polich de Calvo, 1996).

${ }^{17}$ El Territorio. 65 años con el Chaco. Publicación aniversario. 1984.

${ }^{18}$ Ernesto Zamudio (1898-1958) Nació y falleció en Resistencia, Chaco. Maestro y periodista. Luego de cortas experiencias en el diario El Censor y El Constitucional, ingresó a El Territorio en 1925 como director. Enrolado en las filas de la Unión Cívica Radical, fue no obstante muy crítico con los funcionarios del gobierno nacional y territorial durante las décadas de 1920 y 1930. Esto le valió la clausura del diario, la persecución y la cárcel. Durante las décadas de 1940 y principios de 1950 mantuvo su posición opositora al peronismo, lo que le granjeó nuevos problemas y presiones. En 1954 la CGT con apoyo del gobierno compró el diario y Zamudio se alejó de los medios (Echarri, 2003).

${ }^{19}$ El Territorio. 65 años con el Chaco. Publicación aniversario. 1984.

${ }^{20}$ Ildefonso Pérez (1888-1955) Nacido en España, llegó a Barranqueras Chaco en 1916. Autodidacta, de militancia socialista, ocupó cargos políticos en la localidad de Sáenz Peña y trabajó en actividades comerciales y diferentes emprendimientos, algunos vinculados a la publicación de guías y periódicos locales, de la cual Estampa Chaqueña fue la más relevante. Falleció en Resistencia en 1955. (Echarri, 2003). 
Solís Carnicer y Maggio. Posibilidades y limitaciones del uso de la prensa como fuente para la reconstrucción de la...

idoneidad de los funcionarios nombrados para el cargo de gobernador, opinando sobre la elección de los concejos municipales y el respeto a su autonomía, denunciando las arbitrariedades cometidas en los periodos eleccionarios y reclamando la representación parlamentaria y luego la provincialización del territorio (Leoni, 2012).

Otras revistas de cierta relevancia han sido Chaco y Formosa, editada por la Asociación de Fomento de los Territorios Nacionales de Chaco y Formosa. Nacida a fines de la década de 1920 como El Chaco, fue una publicación periódica dirigida por J. Reynaldo Perrotto y en sus páginas se registran los asuntos relacionados con el fomento de la actividad algodonera y la protección de la mano de obra chaqueña. Fue una expresión editorial de los intereses económicos y políticos de una de las asociaciones más importantes de la región (Girbal, 2013). La revista Boreal. Revista chaqueña de interés general de la cual solo contamos con ejemplares del año 1947, fue dirigida por un entonces joven periodista Raúl Berneri ${ }^{21}$. Surgió con los objetivos de convertirse en expresión positiva de la dinámica comunidad chaqueña, "un elemento de utilidad para el desenvolvimiento progresista" de la región" ${ }^{22}$. Berneri, que también formaba parte de El Territorio, se explayaba en la revista en cuestiones políticas, defendiendo la necesidad de avanzar en el proceso de provincialización, la restitución de las autonomías municipales y el derrotero de los partidos políticos, sobre todo del peronismo, al cual observaba con ojos críticos.

\section{III- Limitaciones y posibilidades del uso de la prensa como fuente para el estudio de la historia política: el caso de Corrientes y Chaco}

Para los investigadores que nos dedicamos a la historia política de Corrientes y Chaco en las primeras décadas del siglo XX, la prensa resulta una fuente fundamental. Generalmente, luego de plantear y definir el problema de investigación sobre la historia política regional de las primeras décadas del siglo XX y pensar en las posibles fuentes que servirán de información, consultar la prensa escrita surge entre las primeras opciones junto a la documentación oficial.

Ahora bien, una de las primeras dificultades con las que se encontrará el historiador que quiera trabajar con estas fuentes está relacionada con las posibilidades de acceso a las colecciones de las revistas y periódicos. Es muy frecuente que en los archivos oficiales y bibliotecas públicas se encuentren disponibles pocos ejemplares de la mayoría de las publicaciones y en los casos en que las colecciones se encuentren completas, las condiciones de conservación son muy precarias, a menos que haya pasado por algún proceso de microfilmado o digitalización, que no es lo habitual. Esta situación se agrava cuando la prensa se convierte - en ciertas etapas del proceso de investigación-

\footnotetext{
${ }^{21}$ Raúl Berneri (1928-2000). Fue un destacado periodista chaqueño. Trabajó en prensa gráfica y en radio. Comenzó como redactor en El Territorio entre 1941 y 1954, al cual renunció tras la expropiación del diario por parte del Estado. Volvió en 1955 tras el derrocamiento de Perón y luego fue designado como director de la agencia Télam en Chaco. Creó las revistas Nueva Provincia y Boreal, entre otros emprendimientos. El Museo de Medios de Comunicación de la provincia del Chaco lleva su nombre. (Echarri, 2003).

${ }^{22}$ Boreal. Revista chaqueña de interés general. Resistencia, abril 1947.
} 
en la única fuente disponible. El Archivo General de la provincia de Corrientes cuenta con una importante hemeroteca que resguarda publicaciones desde mediados del siglo XIX, sin embargo, en los últimos años, debido al mal estado de conservación de los ejemplares, se ha restringido el acceso a la prensa anterior a 1960, lo que afectó el desarrollo de muchos proyectos. La posibilidad de digitalización a través de fotografías favoreció el trabajo con este tipo de fuentes porque evita su deterioro por la permanente manipulación, de todas formas, se trata de iniciativas particulares y/o aisladas que dependen de los intereses de los investigadores que hacen uso de esas fuentes. En el Archivo Histórico de la provincia del Chaco, los dos principales periódicos - La Voz del Chaco y El Territorio- se hallan microfilmados y digitalizados y sólo en el caso del segundo es posible consultar los ejemplares en papel en sala. Sin embargo, más allá de que esto implicó un importante avance, todavía el Archivo no ofrece opciones de consulta vía internet.

En el caso de la provincia de Corrientes no constituye un problema menor la enorme variedad y heterogeneidad de su prensa, puesto que, si bien consultar diferentes publicaciones permite tener un panorama un poco más completo de los procesos investigados, se convierte por momentos en una tarea imposible de abarcar en su totalidad. En el caso chaqueño, la dificultad se encuentra en que no se han conservado muchas de las publicaciones, aunque podemos observar que en los diferentes fondos documentales es posible hallar ejemplares sueltos o recortes que dan cuenta de su existencia.

Otra dificultad con la cual nos encontramos quienes trabajamos con la prensa en estos espacios provinciales y regionales, es la escasez de estudios previos que funcionen como apoyo para la investigación -más allá de los casos citados en el cuerpo de este trabajo-. Hacen falta estudios que reconstruyan las condiciones históricas de surgimiento, los itinerarios, actores relevantes, las diferentes tendencias manifestadas en las líneas editoriales de los periódicos, las características morfológicas, fuentes de financiamiento, redes de relaciones entre los directores y periodistas con organismos estatales y asociaciones de diferente tipo, en fin, una historia de la prensa de estas provincias. Esta situación limita las posibilidades de uso de esta fuente pues hace necesario que el historiador haga previamente una indagación sobre el medio a utilizar para luego poder usarlo en su investigación.

Por otro lado, es poco común que los historiadores reflexionen críticamente acerca de las características de la prensa en tanto fuente y que ello sea explicitado en los resultados de su investigación. Si hiciéramos un breve repaso sobre las obras publicadas en las últimas décadas, al menos desde el ámbito académico correntino y chaqueño, todavía los historiadores utilizamos indistintamente los datos que emanan de diferentes periódicos y revistas, sin dedicarle más que unas pocas líneas a las trayectorias e intereses de los medios que citamos. Esto constituye un problema significativo puesto que como señalamos, la prensa -como toda otra fuente- debe ser entendida y analizada en su contexto. Muchas veces, en especial cuando no se cuenta con otra documentación, de no realizar una profunda reflexión sobre la prensa utilizada, el historiador puede 
Solís Carnicer y Maggio. Posibilidades y limitaciones del uso de la prensa como fuente para la reconstrucción de la...

llegar a reproducir acríticamente en su trabajo el discurso de la fuente derivando en conclusiones sesgadas o equivocadas.

A pesar de las limitaciones que esta fuente ofrece, recurrir a la prensa puede ser de mucha utilidad para la reconstrucción de la Historia Política, más aún en los espacios locales o regionales como Corrientes y Chaco en los que muchas veces para algunos períodos no se cuenta con otra documentación. Como hemos mencionado, diversas iniciativas que implican la transformación de la vida política y social de las comunidades (sanción de leyes, reclamos, movilizaciones, defensa de intereses territoriales, entre otros), encuentran en las páginas de la prensa un canal de debate y discusión, donde los directores y redactores se involucraban activamente.

Resulta especialmente una fuente fundamental para la historia de los partidos políticos ya que permite reconstruir su vida interna, conocer sus líderes y actividades. Generalmente, como vimos en los apartados previos, cada sector político se ocupaba de tener un órgano de difusión lo que facilita su caracterización. No es frecuente que los partidos políticos conserven intacta su documentación, de ahí que la prensa cobra otra relevancia ya que a través de ella se puede conocer indirectamente el funcionamiento interno de las agrupaciones, las reuniones, resoluciones de asambleas, comunicados, notas o cartas, invitaciones, anuncios, organización de la afiliación, entre otros aspectos que los partidos enviaban para su difusión. A través de noticias reproducidas en los diarios y revistas se puede acceder a un registro más o menos pormenorizado de las actividades que los partidos realizaban tanto en época de elecciones como durante los períodos intermedios.

Por otra parte, la prensa nos permite recrear el mapa de actores y referentes de la política, individuales y colectivos, sus condiciones de emergencia, sus intereses, sus decisiones y formas de organización. Podemos encontrar los listados de las comisiones directivas de los partidos, las listas de candidatos, las plataformas electorales, las actividades de campaña, etc. Sobre los procesos electorales, los datos que brindan estos medios generalmente es muy detallada, se ofrecen número de empadronados, resultados electorales, denuncias, análisis post electorales, etc. Por otra parte, la información que proveen los periódicos, en muchos casos reemplaza a la información oficial. La publicación de decretos, leyes, discursos de funcionarios o incluso de debates parlamentarios -en algunos transcriptos in extenso- permite recuperar cuando no es posible consultar la documentación producida o editada por el Estado, en una época determinada.

Los periódicos, en su mayoría órganos partidarios, fueron no solo medios a través de los cuales se hacía propaganda política, se transmitía información y el mensaje de los diferentes partidos, sino que también ellos fueron protagonistas de la vida política. A través de sus páginas se delinearon identidades políticas y se establecieron las diferencias entre los sectores y colaboraron en la definición de los temas sobre los cuales giraron los debates políticos de la época. A través de la prensa se puede reconstruir el universo de las prácticas políticas, las ideas emergentes en los discursos, establecer los rasgos identitarios, temas en debate, etc. Además, es posible observar las relaciones entre gobierno y oposición, pues no sólo ayudan a delinear la construcción que el 
diario hacía del grupo al que representaba sino también su posición sobre el adversario. Generalmente, más allá de las noticias que se publicaban siempre aparecía un editorial en el que el que el medio tomaba posición sobre algún problema del momento, analizar esos editoriales permite reconstruir imaginarios, temas en debate e ideas defendidas por los diferentes sectores políticos.

Asimismo, a través de la prensa se puede observar el funcionamiento de otras instituciones políticas y los pormenores del contexto político y social que permiten comprender con más claridad el proceso que se está analizando. En la prensa, generalmente también se publicaban noticias nacionales e internacionales que ayudan a contextualizar con mayor claridad los procesos locales y establecer sus vínculos y relaciones. Además, se pueden cruzar los datos que diferentes periódicos ofrecen de un mismo acontecimiento y de ese modo reconstruirlo desde diversas perspectivas.

En síntesis, la relevancia de la prensa para la reconstrucción de la historia política de Chaco y Corrientes es indudable, tal como lo demuestran todos los trabajos de los investigadores locales e incluso los nuestros. Sin embargo, son muy pocos los que toman a la prensa como objeto de investigación y menos aún, los que se han dedicado a reflexionar críticamente sobre la misma. Tarea que nos propusimos empezar a realizar en este trabajo.

\section{Referencias bibliográficas}

Alonso, P. (Comp.) (2004) Construcciones impresas, Panfletos, diarios y revistas en la formación de los estados nacionales en América Latina (1870-1920). Buenos Aires, Fondo de Cultura Económica.

Aróstegui, J. (2001) La investigación histórica: Teoría y método, Barcelona, Crítica.

Borrat, H. (1989) "El periódico, actor del sistema político". Anàlisi, Quaderns de comunicació i cultura, $\mathrm{N}^{\circ} 12$, Universitat Autònoma de Barcelona, pp. 67-80.

Borrat, H. (1989) El periódico. Actor político. Barcelona, Gustavo Gil.

Braudel, F. (2002) Las ambiciones de la historia. Barcelona, Crítica.

Da Orden, L. y Melon Pirro, J. (comps.) (2007) Prensa y Peronismo. Discursos, prácticas, empresas 1943-1958. Prohistoria Ediciones. Rosario.

Duncan, T. (2007) "La prensa política: Sud- América: 1884- 1892". Revista de Instituciones, Ideas y Mercados $\mathrm{N}^{\circ}$ 46, mayo, pp. 65-92.

Echarri, F. (2003) Periodistas del Chaco. Crónicas de vida. Resistencia, Ed. del autor.

Feris, G. (1992) Testimonio sobre política y periodismo, de 1930 a 1992. Diálogos con Antonio Emilio Castello. Buenos Aires, Plus Ultra.

Girbal- Blacha, N. (2013) "Entre la información y el control social: El algodón en los medios gráficos especializados. Argentina, 1920-1940”. Secuencia, $\mathrm{N}^{\mathrm{o}} \quad 85$, pp.13-44. URL:http://www.scielo.org.mx/scielo.php?script=sci_ arttext\&pid=S018603482013000100002\&lng=es\&nrm=iso 
Solís Carnicer y Maggio. Posibilidades y limitaciones del uso de la prensa como fuente para la reconstrucción de la...

Kircher, M. (2005) "La prensa escrita: actor social y político, espacio de producción cultural y fuente de información histórica". Revista de Historia, $\mathrm{N}^{\mathrm{o}} 10$, Universidad Nacional del Comahue, Neuquén, pp.115- 122.

Leoni, M. S. (2000) "Prensa y opinión pública en el Territorio Nacional del Chaco. El caso de Estampa Chaqueña (1929-1943”). En: XIX Encuentro de Geohistoria Regional. Corrientes, UNNE.

Leoni, M. S. (2001) "Los Territorios Nacionales." En: Academia Nacional de la Historia, Nueva Historia de la Nación Argentina. Vol. VIII, Buenos Aires, Planeta, pp. 43- 76.

Leoni, M. S. (2002) "La política en los territorios nacionales argentinos. La inserción de los municipios del Chaco (1884-1951)". Revista Historia de América, Instituto Panamericano de Geografía e Historia. $N^{\circ} 131$, México DF, julio-diciembre.

Leoni, M. S. (2008a) "La política en el Chaco en la primera mitad del siglo XX. Estructuras de participación, actores y prácticas”. En: Iuorno, G. y Edda Crespo (coord.). Nuevos Espacios- Nuevos Problemas. Los Territorios Nacionales. Universidad Nacional de la Patagonia "San Juan Bosco", Universidad Nacional del Comahue y Centros de estudios de Estado, Política y Cultura.

Leoni, M. S. (2008b) La conformación del campo cultural chaqueño. Una aproximación. Corrientes, Moglia Ediciones.

Macor, D. (2014) "Testigo y protagonista. Un diario de provincia en la construcción del campo de lo político. El Litoral, Santa Fe, 1918- 1966". Estudios Sociales, 46, Santa Fe: Universidad Nacional del Litoral, 313- 330. DOI: https://doi. org/10.14409/es.v46i1.4485

Maeder, E. J. A (1997) Historia del Chaco. Plus Ultra. Buenos Aires.

Méndez Paz, E. (1953) Periódicos correntinos 1825- 1900. Buenos Aires.

Morán, D. y Aguirre, M. I. (2008) "La prensa y el discurso político en la historia peruana: algunas consideraciones teóricas y metodológicas". Investigaciones Sociales, Año XII, No20, UNMSM/IIHS, Lima, pp. 229- 248.

Palacio Montiel, C. del (2006) "La prensa como objeto de estudio. Panorama actual de las formas de hacer historia de la prensa en México". Comunicación y Sociedad, $\mathrm{N}^{\circ}$ 5, enero-junio, Universidad de Guadalajara Zapopan, México pp. 11-34.

Panella, C. (2000) "El peronismo según el Diario La Prensa en tiempos de la Revolución Libertadora (1956-1958)". Anuario del Instituto de Historia Argentina, $\mathrm{N}^{\circ} 1$, pp.109-122. En Memoria Académica, FaHCE - UNLP. Disponible en: http:// www.memoria.fahce.unlp.edu.ar/art_revistas/pr.2912/pr.2912.pdf

Panella, C. (2000) "El peronismo según el Diario La Prensa en tiempos de la Revolución Libertadora (1956-1958)". Anuario del Instituto de Historia Argentina, $\mathrm{N}^{\circ} 1$, 109-122. Disponible en: http://www.memoria.fahce.unlp.edu.ar/art_revistas/ pr.2912/pr.2912.pdf

Panella, C. (2004) "La Vanguardia y el surgimiento del peronismo (1943-1945)". Anuario del Instituto de Historia Argentina $\mathrm{N}^{\circ} 4$, Facultad de Humanidades y Ciencias de la Educación de la Universidad Nacional de la Plata. La Plata. 
Pasquali, P. (2001) “E1 Periodismo (1852-1914)”. En: Academia Nacional de la Historia, Nueva Historia de la Nación Argentina, Vol. 6. La configuración de la república independiente (1810-c-1914). Buenos Aires, Planeta.

Polich de Calvo, L. (1996 - 1998) Hombres y mujeres que hicieron Chaco. Tomos I y II. Encarnación, Paraguay, Ed. del autor.

Prislei, L. (comp.) (2001) Pasiones Sureñas. Prensa, cultura y política en la Frontera Norpatagónica (1884-1946), Buenos Aires, Prometeo.

Rein, R. y Panella, C. (comps.) (2008) Peronismo y prensa escrita. Abordajes, miradas e interpretaciones nacionales y extranjeras. Editorial de la Universidad de La Plata, La Plata.

Saítta, S. (1998) Regueros de tinta. El diario Crítica en la década de 1920. Sudamericana, Buenos Aires.

Sanchez de Larramendy, M. I. (1988) “Los primeros años del periodismo de Resistencia: El Colono". En: Encuentro de Geohistoria Regional, 7 al 8 de agosto 1987. IIGHI, Instituto de Investigaciones Geohistoricas, Resistencia, pp. 283-294

Sánchez de Larramendy, M. I. (2006) "Los periodistas extranjeros de la colonia Resistencia a fines del siglo XIX y principios del XX”. Revista de la Junta de Estudios Históricos del Chaco, $\mathrm{N}^{\circ}$ 3, Subsecretaría de Cultura del Chaco, Resistencia, pp. 31-52.

Sidicaro, R. (1993) La política mirada desde arriba. Las ideas políticas del diario La Nación. 1909- 1989. Sudamericana, Buenos Aires.

Sidicaro, R. (2009) La política mirada desde arriba. Las ideas del diario La Nación 1909-1989. Buenos Aires, Sudamericana.

Sirvén, P. (2011) Perón y los medios de comunicación (1943-1955), Centro Editor de América Latina, Buenos Aires, [1984]. Edición corregida y aumentada. Sudamericana. Buenos Aires.

Solís Carnicer, M. del M. (2013) "El peronismo en la provincia de Corrientes: orígenes, universo ideológico y construcción partidaria (1943-1949)". En: D. Macor y C. Tcach. La invención del peronismo en el interior del país II. Santa Fe, Ediciones Universidad Nacional del Litoral.

Solís Carnicer, M. del M. (2006) La cultura política en Corrientes. Partidos, elecciones y prácticas electorales. (1909- 1930). Tesis Doctoral. Facultad de Filosofía y Letras, Universidad Nacional de Cuyo. URL http://bdigital.uncu.edu.ar/bdigital/ fichas.php?idobjeto $=2756$

Solís Carnicer, M. del M., Chao, D. y Ayala, B. (2013) "Prensa y política en Corrientes. Una aproximación a los periódicos correntinos del período 1909- 1930" En: Anales de la Junta de Historia de la provincia de Corrientes $N^{o} 15$, Corrientes, Moglia Ediciones, 2013. pp. 240- 265.

Tato, M. I. (2004) Viento de Fronda. Liberalismo, conservadurismo y democracia en la Argentina, 1911- 1932. Buenos Aires, Siglo XXI.

Ulanovsky, C. (1997) Paren las rotativas. Historia de los grandes diarios, revistas y periodistas argentinos. Buenos Aires, Espasa. 
Varela, M. (2002) "Peronismo y medios: control político, industria nacional y gusto popular". Cuadernos de ReHiMe - Periodismo y Medios. Buenos Aires.

Vezzosi, J. (2013) "El diario El Liberal y el surgimiento del peronismo santiagueño (1945-1946)". Trabajo y Sociedad. Sociología del trabajo - Estudios culturales - Narrativas sociológicas y literarias. Santiago del Estero.

Zimmermann, E. (1996) "La prensa y la oposición política en la Argentina de comienzos de siglo: El caso de La Nación y El Partido republicano". Estudios Sociales. Año 3, $\mathrm{N}^{\mathrm{o}}$ 15. Santa Fe. 